passengers in a light truck (compared to sedan) had higher odds of rear seatbelt use in Bandung, while a belted front passenger was associated with rear seatbelt use in Bangkok.

Conclusions Rear seatbelt use was low in Bangkok and even lower in Bandung. Gender, age, and the behavior of other occupants were key predictors of rear seatbelt use.

Learning Outcomes Findings highlight the need for rear seatbelt laws in Bandung and improved enforcement of existing rear seatbelt laws in Bangkok.

\section{A.006 ROAD SAFETY PEER EDUCATION IN BELGRADE - AN EXAMPLE OF GOOD LOCAL PRACTICE}

Marija Markovic*, Nevenka Kovacevic, Svetlana Mladenovic Jankovic, Gordana Tamburkovski, Andjelka Brkovic, Dusanka Matijevic. Institute of Public Health of Belgrade, Belgrade, Serbia

10.1136/injuryprev-2021-safety. 188

Background Road traffic injuries are the leading cause of death and disability at the age of 15-19. Accordingly, the Institute of Public Health of Belgrade introduced peer education on road safety in Belgrade's high schools. Since November 2016, 13 educations with 665 participants have been held. The aim of our research was to evaluate the impact of peer education on road safety knowledge of high school students.

Methods A field survey was conducted in the period JanuaryDecember 2018. The 218 peer education participants completed pre and post-test of knowledge. SPSS -20 was used for statistical analysis. Hi-square test was used to compare the pre and post-tests results.

Results The advancement in knowledge was noticeable in our aspects of road traffic behavior, especially the knowledge of the correct emergency services numbers. After the education, the percentage of incorrect answers to this question was almost twice lower - only 7, 4\%, ( $<<0.001, \chi 2=77,654)$. Also, the percentage of those not knowing the proper treatment of injured decreased significantly $(\mathrm{p}<0.001, \chi 2=$ 33.683).

Conclusion Study results have shown the improvement of knowledge among high school students and confirmed the fact that peer education is an effective way of transferring and acquiring knowledge and skills in the field of road safety since the message is transferred through the age-adjusted language, which makes it more accessible to the target population.

Learning Outcomes Our study indicates the need to increase the coverage of older adolescents with this type of education.

\section{A.007 EVALUATING THE IMPACT OF A ROAD SAFETY EDUCATION PROJECT IN MADAGASCAR SCHOOLS}

${ }^{1}$ Paolo Perego*, ${ }^{1}$ Federica Biassoni, ${ }^{2,3}$ Ana Luisa Silva, ${ }^{4}$ Sam Clark, ${ }^{3}$ Jesse Randrianarisoa ${ }^{1}$ Traffic Psychology Unit of Research, UCSC, Milan, Italy; ${ }^{2}$ CESA - ISEG Centro de Estudos sobre África e Desenvolvimento, Universidade de Lisboa, Lisbon, Portugal; ${ }^{3}$ ONG Lalana, Antananarivo, Madagascar; ${ }^{4}$ Transaid, London, UK

\subsection{6/injuryprev-2021-safety. 189}

Context Road crashes are the leading cause of death for children and young adults aged 5-29 worldwide. Education is an important part of a safe systems approach to improve road safety. However, evaluating the effectiveness of road safety education projects is challenging. This presentation shares the experience of a quasi-experimental approach to assess the impact of an NGO project implemented in six primary schools in Antananarivo, Madagascar, between 20172018.

Analysis The project evaluation was conducted in August 2019. Photos showing nine Malagasy road crossing scenarios were presented to students in random order. Students should consider that they were in the perspective of the person who took the photo and wanted to cross the road. They must therefore indicate the areas of the photo where they would look at first, at second and third.

Outcomes Data was analyzed for two samples: 250 students from project participant schools and 300 students from other schools in the same city. The number of students able to apply the correct rules for different road crossing scenarios (look first left, second right and left again before crossing) was on average $20 \%$ higher in project participant schools.

Learning Outcomes The results of this impact assessment, combined with a separate teacher evaluation, will contribute to a revision of the techniques used by the NGO to build teacher capacity and to teach students to correctly apply the rules when facing a real situation. The methodology is a cost-effective tool to evaluate the impact of road safety education in schools.

\section{A.008 CO-DESIGN: DEVELOPING A DECISIONAL SUPPORT RESOURCE FOR OLDER AUSTRALIAN DRIVERS}

Nadine Veerhuis*, Victoria Traynor, Melanie Randle. University of Wollongong, Wollongong, Australia

\subsection{6/injuryprev-2021-safety. 190}

Context A multiplicity of issues impact older driver decisionmaking when self-regulating driving behaviour. Ensuring decisions are timely, so that safe driving is maintained, requires engagement with a diverse range of health practitioners. Regardless, decisions are also underpinned by demographics, psycho-social and environmental factors. The complexity of issues impacting driving decisions lends to an equivalent codesign approach to the development of a decisional support resource.

Process Systematic reviews and empirical data collection informed discussions for six workshop collaborations engaging end-users, stakeholders and diverse professional groups. Iterative synthesis of outputs to inform core concepts for the content and format of the resource were produced at each workshop, using participatory action research methodology.

Analysis Workshop collaborations were conducted with two separate groups each on three occasions over eight months. Older drivers $(\mathrm{N}=8)$ comprised the core senior community group. A diverse range of health professionals and academics $(\mathrm{N}=10)$ from seven distinct domains and two transport safety specialists comprised the core advisory panel.

Outcomes A decisional support resource unique to the Australian context was developed with, and for, older drivers in collaboration with health professionals, academics and transport safety specialists.

Learning Outcomes Co-design approaches rarely involve engagement of multiple and diverse groups in the 